\title{
Object Model of Quality of Medical Instrument Traceability System Based on Finite State Machine
}

\author{
Liquan $\mathrm{Han}^{1, *}$, Zhengchao $\mathrm{Xu}^{1}$ and Xiaobo Wang ${ }^{2}$ \\ ${ }^{1}$ College of Computer Science and Engineering Changchun University of Technology Changchun P.R. China \\ ${ }^{2}$ Fuying Hospital of Siping Siping P.R. China \\ ${ }^{*}$ Corresponding author
}

\begin{abstract}
With the continuous improvement of medical level, the demand for medical Instrument is increasing year by year, it is necessary to trace on the quality and safety of medical Instrument. Establish the traceability of the medical instrument can not only reduce the medical incidents and suppress the spreed of the counterfeit or unqualified medical instrument, but also help the enterprises to find source problem and determine the flow of the same batch of products, notice the relevant enterprises to take measures after problem products appear and finally assure the customers' rights and interests. In this paper, has been adopted the technology of Radio Frequency Identification and the Electronic Product Code and the thought of Finite State Machine, puts forward a object module of medical instrument traceability system based on the research of internet of things technology and the architect of product traceability support system, realize the integration and information exchange between various roles in the industrial chain of medical consumables. Finally, the prototype system was designed and implemented to verified the quality traceability of medical instrument.
\end{abstract}

Keywords-medical instrument; quality and safety tracing; rule database; finite state machine

\section{INTRODUCTION}

With the improvement of medical treatment level, large scale operation and treatment can be carried out in medical treatment, and the corresponding medical equipment and medical materials have been widely used. Medical consumables is refers to the hospital in the process of providing medical services to patients, by a use value and cost into the cost of material [1]. Medical consumables is an important part of medical equipment, occupies a large proportion in medical equipment. The traceability of medical device products is not only the request of the general consumers to the service provider, but also the requirement of the national laws and regulations. Formulated by the national drug regulatory authority organization "medical device adverse event monitoring guidelines (Trial) "clearly put forward: medical device manufacturing enterprise and the use of unit shall establish a product traceability system [2]. Medical equipment monitor aims to medical equipment in the process of using the suspicious adverse events of collecting, reporting, analysis and evaluation, find and identify post-marketing risk of unreasonable of medical apparatus and instruments. Medical apparatus and instruments of unsafe take effective control measures to improve the safety of the product, damage to prevent a repeat and spread, so as to ensure the safety of the public with machinery.

As the consumption of medical products market demand, production technology is not high, more likely to be inferior product counterfeiting. Through monitoring and evaluation of the medical device tracking, it can provide the regulatory basis for the medical equipment supervision management department, and improve the related standards, to promote enterprise to development and promotion of new products, promote the sustained and healthy development of China's medical equipment industry.

RFID is a wireless non-contact communication technology which uses radio-frequency electromagnetic fields to transfer data, for the purposes of automatically identifying and tracking tags. The Electronic Product Code (EPC) is designed as a universal identifier that provides a unique identity for every physical object anywhere in the world, for all time. Its structure is defined in the EPCglobal Tag Data Standard[3][4], which is an open standard freely available for download from the website of EPCglobal, Inc..

In this paper, based on the Internet of things technology, by state food and drug supervision bureau in 2015, the newly revised "medical equipment production and the quality control standard" as guidance, to medical equipment product tracking process as the research content, the traceability of production distribution - use - destroy the technical route, medical apparatus and instruments product tracking information model is put forward.

\section{FINITE STATE MACHINE MODEL}

Any currently executing program, at any given time have a state. When a program that is being executed changes its state is called "change". If we have identified a program all the status, events and changes, we can completely for the program to establish a Finite State Machine (FSM) model. FSM is a discrete mathematical model with discrete input and output system. It is in a particular state at any time, and the number of these States is limited. For event driven programming, it is very useful to design a model that is convenient to solve some practical problems, such as the application of digital circuits and network communication.

FSM has two kinds of state machine, deterministic state machine, a kind of dispute it for each input can have multiple state for transfer; The other is a deterministic state machine, it 
is only a status for each input for transfer. In this paper, the finite state machine is a deterministic finite state machine.

Used mathematical thinking to describe the words, it can put FSM as a five tuple:

$$
\mathrm{S}=(\mathrm{Q}, \Sigma, \delta, \mathrm{q}, \mathrm{F})
$$

Where:

(1) $\mathrm{Q}=\{\mathrm{q} 0, \mathrm{q} 1, \cdots, \mathrm{qn}\}$ represent the state of non empty a finite set. For arbitrary $q(q \in Q)$, called for a state $S$. In any definite time, FSM can only receive a certain input that qi.

(2) $\Sigma$ represent finite input event table, $\Sigma=\{\mathrm{I} 0, \mathrm{I} 1, \ldots, \mathrm{Im}\}$ represent a finite input event set. In any definite time, FSM can only receive a certain input that Ii.

(3) $\delta$ represent the state transition function, sometimes called state conversion function or mobile function, usually with formula Delta: $\delta: \mathrm{Q} \times \Sigma \rightarrow \mathrm{Q}$ or $\delta(\mathrm{qi}, \mathrm{Ij})=\mathrm{qj}$ to represent its meaning. That is to say, at a certain moment, finite state machine is a state of qi $(q i \in Q)$, if at this time to receive an input event $\mathrm{Ij}(\mathrm{Ij} \in \Sigma)$ trigger, then finite state machine will be transferred to another to determine the state of qj ( $q j \in Q$ ). If an external event Ii does not exist in the event table, FSM will not do any transfer.

(4) q0 represent S start state, can also be called the initial state or start start. For any q0 $(\mathrm{q} 0 \in \mathrm{Q}), \mathrm{FSM}$ which state began to receive external input events.

(5) $\mathrm{F}$ represents a collection of $\mathrm{S}$ termination states. In a broad sense, $F$ is a subset of $Q$. For any $q(q \in Q)$ is called the end state S. FSM in the transfer to the final state, it is said that the end of the transfer, and then there will be no external event trigger transfer.

\section{MEDICAL EQUIPMENT LIFE CYCLE STATE TRACE ANALYSIS}

\section{A. Full Life Cycle Analysis of Medical Equipment}

Product lifecycle management (PLM) refers to the demand for products from the beginning, to eliminate all of the life of the product obsolete [5]. According to the definition of PLM, and combined with the actual needs of the hospital management, medical device life cycle is defined as: starting from the medical source material procurement, through the processing of production enterprises, logistics transportation, dealer sales, finally use the hospital for the patients after the end of the whole life course. In this process, the medical device is in the actual flow between different enterprises and users, so the medical device industry chain of all enterprises is to achieve tracking system needs to deal with business objects.

Every link of medical equipment life cycle will affect its safety, regulatory oversight of any link will lead to security risks. And the medical devices industry chain as an important part of the life cycle of medical security system, is the impact of carrier safety factors, so the safety risk of medical devices at the end of the supply chain management and effective control. Medical device industry chain involves many enterprises, but according to its functions can be divided into suppliers, manufacturers, distributors, hospitals and consumers, and other components. Typically, medical devices from the factory to enter the medical institutions, most of the experience of such a chain: manufacturers, wholesalers, logistics and distribution enterprises, medical institutions or retailers, consumers (patients).

The whole life cycle can be roughly divided into three stages: Production stage, Circulation phase and Use phase. The production stage, starting from raw material procurement, production by production enterprises into the factory, which is also the core stage, because the quality of medical consumables in the production process is the key to meet the quality requirements, at the same time this stage also involves a large number of data, these data will be the basis for quality tracing; The circulation stage, the factory's products from the manufacturer to the hospital circulation stage, this stage and quality related data are not many, may cause quality problems in the stage of the product in the warehouse in the storage and transportation process conditions for compliance with the conditions of transport; The use of the stage, that is, the process of using the product in the patient's body, the process before the use of products and testing, may also lead to product problems.

\section{B. Medical instrument quality tracking business object model}

In the whole life cycle of medical devices involved in the business object is more complex. Need to focus on the establishment of production enterprises, circulation enterprises, retailers, pharmaceutical suppliers, hospitals and patients (users) business objects. Establish business relationship between object model and the model object. The main business object model is shown in figure 1 .

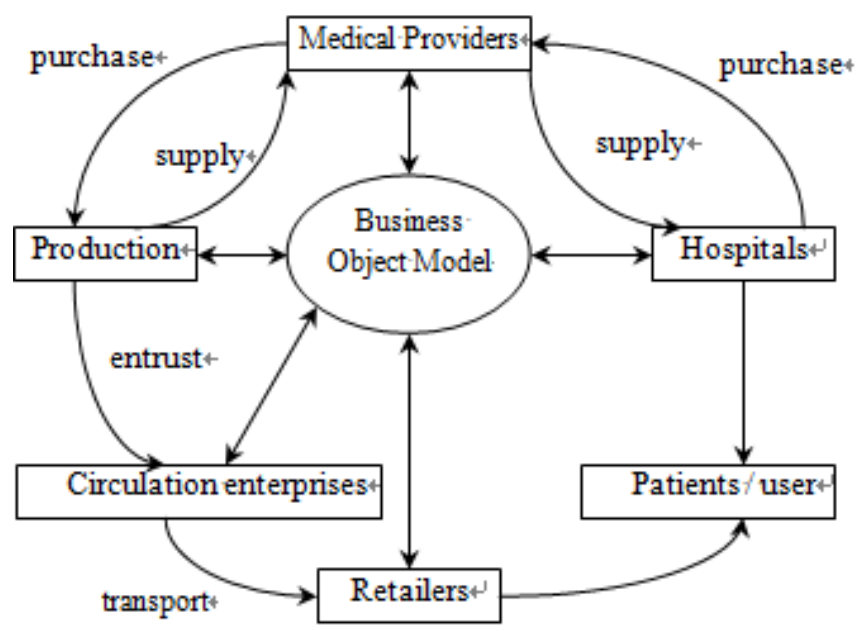

FIGURE I. MEDICAL INSTRUMENT QUALITY TRACING BUSINESS OBJECT MODEL

From the analysis of the medical device industry chain can be found in this business includes many links: from production, to the logistics enterprises, and then to the vendors, and finally to the hospital for patient use. This process can be divided into two kinds of medical device tracking: one is the tracking process from top to bottom, mainly through the RFID label on 
each link from production to the track and the main data related information collection. The other is the tracking process from bottom to top, it can be divided into two aspects. On the first hand, when the consumer hospital or other intermediate users get the device can be a detailed information on the device product inquiries; The second aspect is that when the device product problems, can be traced through the product number, so as to find the cause of the problem.

Medical device tracking the implementation of the principle is: the information about the medical equipment according to certain encoding rules stored in various types of tags, Then, it identifies the information in the tag by sensing technology and transmits it to the database. Through the tracking and tracing of the medical device circulation link, to achieve the goal of medical device tracking, to achieve the quality of medical equipment from the production to the whole process of the whole process of quality control.

\section{Medical instrument quality tracking information object model}

Medical equipment quality information traceability is the basis of the basic data and data sharingm. Medical supplies quality traceability system needs to establish a smooth flow of quality information flow with the relevant role of enterprises, from the relevant enterprises to obtain quality information. Between the various enterprises in the core of the production enterprise, from the supplier to the hospital, the center also includes the cooperation partners, these enterprises have interaction. The quality information flow tracing structure model of medical consumables is shown in figure 2 .

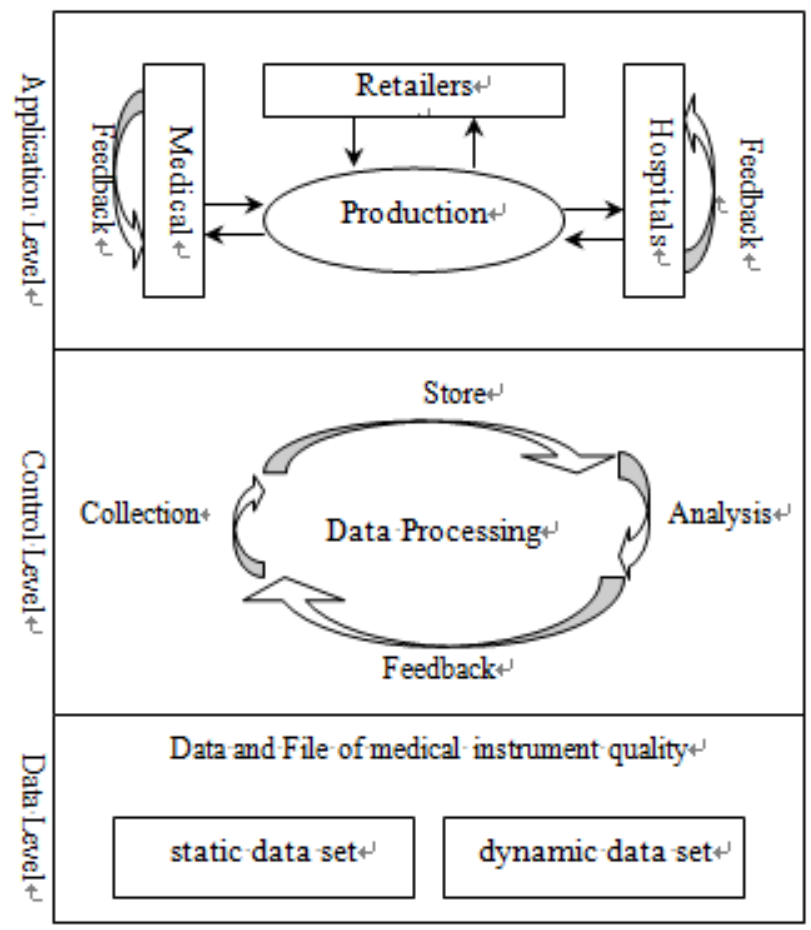

FIGURE II. MEDICAL INSTRUMENT QUALITY TRACING INFORMATION OBJECT MODEL
The information flow in the whole life cycle includes static data and dynamic data. In the performance of macro products between the various roles between enterprises and enterprises of various roles transfer interaction; at the micro level performance for different levels of information collection, information storage, information analysis, information feedback loop.

Medical supplies information can be divided into two parts by retrospective purposes: One is the basic information related to the product, including the basic information of the product itself, as well as the information of the process of recording the process of the product. The basic information of products like product number, quantity and specification; records of product information including product experience experience the role of enterprise information, the information is responsible for handling, from the production process information and so on; The two is related to the quality of medical supplies information data, such as the production process of a specific process in the process of industrial parameters, the use of pre processed data, etc.. Definition of quality traceability process information for medical consumable materials as shown in formula 1:

$$
E Q F T=\left\{\begin{array}{l}
E \cdot \inf o=\left\{e p_{1} \cdot \inf o \bigcup e p_{2} \inf o \bigcup \ldots \cup e p_{n} \cdot \inf o\right\} \\
e p_{i} \cdot \inf o=\left\{w_{1} \cdot \inf o \bigcup w_{2} \cdot \inf o \bigcup \ldots \cup w_{n} \cdot \inf o\right\} \\
w_{i} \cdot \inf o=\left\{p_{1} \cdot \inf o \bigcup p_{2} \cdot \inf o \bigcup \ldots \cup p_{n} \cdot \inf o\right\} \\
p_{i} \cdot \inf o=\left\{r \cdot \inf o \bigcup Q_{c}\right\}
\end{array}\right\}
$$

where:

E - a collection of aggregate information data set;

EP - on behalf of the medical supplies related to the role of enterprise information data set collection;

W - on behalf of the workshop;

$\mathrm{P}$ - represents the specific process;

$\mathrm{R}$ - represents the relationship information data,

Qc - representative of the process of the specific quality information data.

Here, we can carry out the process of circulation transfer between enterprises (from one enterprise to another business) as a product through specific processes, and the whole process is represented by the formula.

\section{MEDICAL INSTRUMENT QUALITY TRACKING SYSTEM STATE MACHINE IMPLEMENTATION MODEL}

FSM is a conceptual machine that can take some action to respond to an external event. The operation of the specific operation not only depends on the received event, but also depends on the relative occurrence of each event. The response to an event depends not only on the event itself, but also on the internal state of the machine, which can be modeled as a series of event / state combinations. Based on the analysis of the process of the object model, the medical equipment in different roles between the flow, the transformation of different states, and from time to time back to the last state. Therefore, it is 
suitable to use the FSM state model to describe the state of the transition. The description table of the state table and event in the system operation process is shown in the following table.

TABLE I. SYSTEM RUNNING STATE SCRIPT

\begin{tabular}{|c|c|}
\hline State & State script \\
\hline $\mathrm{q}_{0}$ & No login / consumer query \\
\hline $\mathrm{q}_{1}$ & Query By traceability code \\
\hline $\mathrm{q}_{2}$ & Query By other way \\
\hline $\mathrm{q}_{3}$ & Traceability information management \\
\hline $\mathrm{q}_{4}$ & Sub system \\
\hline $\mathrm{q}_{5}$ & Message Operations \\
\hline $\mathrm{q}_{6}$ & Waiting for a response from the server \\
\hline
\end{tabular}

TABLE II. SYSTEM EVENT SCRIPT

\begin{tabular}{|c|c|}
\hline Event & Event script \\
\hline $\mathrm{I}_{1}$ & Click the back button code query \\
\hline $\mathrm{I}_{2}$ & Click the query button in other ways \\
\hline $\mathrm{I}_{3}$ & The administrator login is successful \\
\hline $\mathrm{I}_{4}$ & Employee login is successful \\
\hline $\mathrm{I}_{5}$ & $\begin{array}{c}\text { Click on the corresponding button operation } \\
\text { information }\end{array}$ \\
\hline $\mathrm{I}_{6}$ & Enter the correct information and submit \\
\hline $\mathrm{I}_{7}$ & server responding \\
\hline $\mathrm{I}_{8}$ & server not responding \\
\hline
\end{tabular}

According to Table1 and Table2 description of medical instrument quality traceability model base on FSM can be represented as a tuple below five:

$$
S=\left(\left\{q_{1}, q_{2} \ldots, q_{8}\right\},\left\{I_{1}, I_{2} \ldots, X_{8}\right\}, \delta, q_{0},\left\{q_{7}, q_{8}\right\}\right)
$$

Where:

$$
\begin{array}{ccc}
\delta\left(q_{0}, I_{1}\right)=q_{1} & \delta\left(q_{0}, I_{2}\right)=q_{2} & \delta\left(q_{0}, I_{3}\right)=q_{3} \\
\delta\left(q_{0}, I_{4}\right)=q_{4} & \delta\left(q_{3}, I_{5}\right)=q_{5} & \delta\left(q_{4}, I_{5}\right)=q_{5} \\
\delta\left(q_{1}, I_{6}\right)=q_{6} & \delta\left(q_{2}, I_{6}\right)=q_{6} & \delta\left(q_{5}, I_{6}\right)=q_{6} \\
\delta\left(q_{6}, I_{7}\right)=q_{7} & \delta\left(q_{6}, I_{8}\right)=q_{8} ;
\end{array}
$$

Event-driven state transition process as follows:

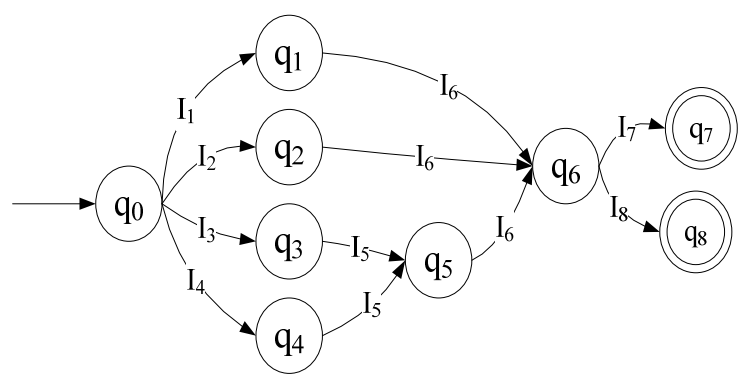

FIGURE III. EVENT-DRIVEN STATE TRANSITION PROCESS

\section{CONCLUSIONS AND FUtURE WORKS}

Based on the research of radio frequency identification technology and EPC coding technology, this paper analyzes the RFID technology, RFID reader technology and anti collision technology. The object model of the medical device traceability system is put forward based on the domestic medical equipment tracing support system. The model, from the point of view of tracing information, realizes the effective management of the whole life cycle of medical devices. Combined with the finite state machine theory, a finite state machine model for medical device tracing is proposed. The model of the medical device tracking user operation in the application system as the state, analyzes the transition conditions between these States, to solve the user take system is not in the expected operation caused by no response. Through the establishment of the corresponding quality traceability model and the use of quality rule base to achieve quality diagnosis method to achieve the quality of medical supplies traceability, can better achieve the quality of medical supplies traceability purposes.

But the tracing model proposed in this paper is not perfect, it is only suitable for the quality of the majority of medical supplies back, for some special circumstances have yet to be further studied; Further research and Analysis on the quality diagnosis of medical consumable materials should be further studied and extended.

\section{REFERENCES}

[1] Li Han. Analyses on the Common-Used Classified Codes of Medical Consumptive Materials. Chinese Journal of Medical Instrumentation[J]. 2012, 36(1) : 69-71.

[2] State Food and Drug Administration. Guidelines for the monitoring of adverse events of medical devices (Trial Implementation). 2011.

[3] Ngai, E. W. T., Moon, K. K. L., Riggins, F. J., \& Yi, C. Y. RFID research: An academic literature review (1995-2005) and future research directions. International Journal of Production Economics, 2008,112(2), 510-520.

[4] EPCglobal. Class 1 Generation 2 UHF Air Interface Protocol Standard Version 1.0.9, 2005. Available from: www.epcglobalinc.org/.

[5] CIMData Inc.. Product lifecycle management[R]. Michigan:CIMData Inc. 2003

[6] REGATTIERI A, GAMBERI M, MANZNI R. Traceability of food products: General framework and experimental evidence[J]. Journal of Food Engineering, 2007, 81(2): 347-356.

[7] HOSSAIN M A. Internet of Things: Principle, Framework and Applicationf[C]. 4th International Conference on Intelligent Information Technology Application, 2010: 132-134.

[8] Judith A. Symonds, David Parry. Using RFID to Track and Trace High Value Products: The Case of City Healthcare[J]. Journal of Cases on Information Technology.2008, 10(1) : 353-366.

[9] Mekean J D.The importance of traceability for public health and consumer protection[J].Revue Seientifique et Teehnique.2001, 20(2) : 363-371.

[10] J P Xu, Y N He, M Gen. A class of random fuzzy programming and its application to supply chain design $[\mathrm{J}]$. Computers \& Industrial Engineering. 2009, 56(3) : 937-950.

[11] Uckelmann, Dieter, Mark Harrison, and Florian Michahelles, eds. Architecting the internet of things. Springer, 2011.

[12] Alam, M. I. Comparative Study of Different Symmetric and Asymmetric Algorithms of Cryptography. International Journal of Advanced and Innovative Research, 2013, 2(11), 632-637.

[13] Bardaki, C., Kourouthanassis, P., \& Pramatari, K. Modeling the information completeness of object tracking systems. The Journal of Strtegic Information Systems, 2011, 20(3), 268-282. 